\title{
Cartography as a tool to assess spatial skills in children aged 3-5 years
}

\author{
Paola Zamperlin ${ }^{\mathrm{a}, *}$, Guenda Mangoni ${ }^{\mathrm{b}}$ \\ ${ }^{a}$ University of Pisa, Italy - paola.zamperlin@ unipi.it \\ ${ }^{b}$ Istituto Sacro Cuore - Fondazione Gérine Fabre, Livorno, Italy-guenda.mangoni94@hotmail.it \\ * Corresponding author
}

Keywords: Maps and Spatial Thinking, Spatial Skills Assessment, Pre-K

\begin{abstract}
:
In this presentation, we discuss a piece of empirical research we recently conducted thanks to a cooperation between the Universities of Pisa and Firenze and a Pre-kindergarten school in Livorno (Tuscany, Italy). The research idea was to assess Spatial Skills of Pre-K children using a map, proposed in two different scales, as an investigation tool.
\end{abstract}

Our research aims at understanding in which ways and according to which phases spatial thinking develops in children, and if it is possible to identify marked differences related to growth, gender, or any evolutionary leaps. The experiment was conducted over a period of approximately six months and delivered significant results. A sample of approximately one hundred children, almost equally divided by age and gender, was examined (Table 1). To ensure that the behaviour and responses of each child were not influenced by external conditioning, the experimentation required the provision of a suitable environment and an appropriate amount of time.

\begin{tabular}{|c|c|c|}
\hline Age & Male & Female \\
\hline 3 years old & 19 & 14 \\
\hline 4 years old & 17 & 16 \\
\hline 5 years old & 14 & 19 \\
\hline Total & 50 & 49 \\
\hline
\end{tabular}

Table 1. Margin settings for A4 size paper

The authors created a map representing an interesting and comfortable place for a child, using symbols as selfexplanatory as possible and then printed the map in two different scales (Figure 1). Subsequently, each child was prompted to observe the two maps and interviewed by the educator following a predefined grid of questions and topics, to test their spatial literacy around the main concepts of scale, distance and direction, symbology, and language (Moran and Moran 2013).

The response analysis offered a clearer picture of the level of spatial skills in the different age groups and, in particular, highlighted a clear evolutionary leap between children aged 3 and 4-5 years.

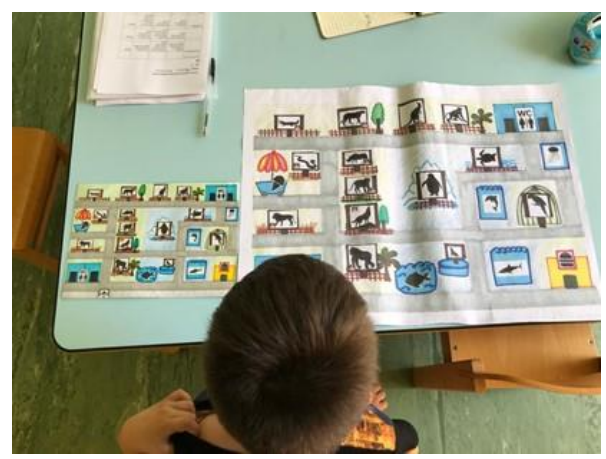

Figure 1. Child observing the two maps at different scales. 


\section{References}

Committee on Support for Thinking Spatially, 2006. Learning to Think Spatially. National Research Council, The National Academies Press, Washington, D.C.

Moran A. and Moran L., 2013. Spatial Thinking About Maps. Development of Concepts and Skills Across the Early Years. Report prepared for National Geographic Education Programs, The National Geographic Network of Alliances for Geographic Education. 